\title{
Reversible urinary retention as the main symptom in the first manifestation of a syringomyelia
}

\author{
Georgios Amoiridis, Saskia Meves, Ludger Schöls, Horst Przuntek
}

\author{
Neurologische Klinik \\ der Ruhr-Universität, \\ St Josef-Hospital \\ Bochum, \\ Gudrunstrasse 56, \\ 44791 Bochum, \\ Germany \\ G Amoiridis \\ $S$ Meves \\ L Schöls \\ H Przuntek \\ Correspondence to: \\ Dr G Amoiridis \\ Neurologische Klinik der \\ Ruhr-Universität, St Josef- \\ Hospital Bochum, \\ Gudrunstrasse 56, 4479 \\ Bochum, Germany. \\ Received 15 December 1995 \\ and in revised form \\ 22 February 1996 \\ Accepted 13 May 1996
}

Left and right tibial nerve SEPs two weeks after onset of urinary retention. Low N24 (L1/iliac crest) potential bilaterally. The L5/iliac crest potential is higher than the N24.

\begin{abstract}
A neurogenic bladder is seldom described as the first manifestation of syringomyelia. A patient is reported with an extensive syrinx along the entire spinal cord and a Chiari type I malformation, who experienced dysaesthesia and weakness during shooting practice and presented with urinary retention.
\end{abstract}

(F Neurol Neurosurg Psychiatry 1996;61:407-408)

Keywords: syringomyelia; Valsalva's manoeuvre; urinary retention; somatosensory evoked potential; F waves

Although it has variable manifestations, syringomyelia has traditionally been considered a chronically progressive disorder clinically manifested by brachial amyotrophy, dissociated sensory loss, neurogenic arthropathies, and long tract signs. Acute onset, accompanied by pain or paresis, is a rare form of manifestation. ${ }^{1}$ A neurogenic bladder is seldom described as the first manifestation. ${ }^{2}$ We report a patient with an extensive syrinx along the entire spinal cord and a Chiari type I malformation, who experienced dysaesthesia and weakness during shooting practice and presented with urinary retention.

\section{Case report}

A 25 year old man was admitted to the hospital after he noticed acute dysaesthesia in his trunk and in all limbs, as well as weakness in his hands and legs during shooting practice. Except for absent deep tendon and superficial abdominal reflexes, the neurological and physical examination in the emergency room was considered unremarkable and the patient left

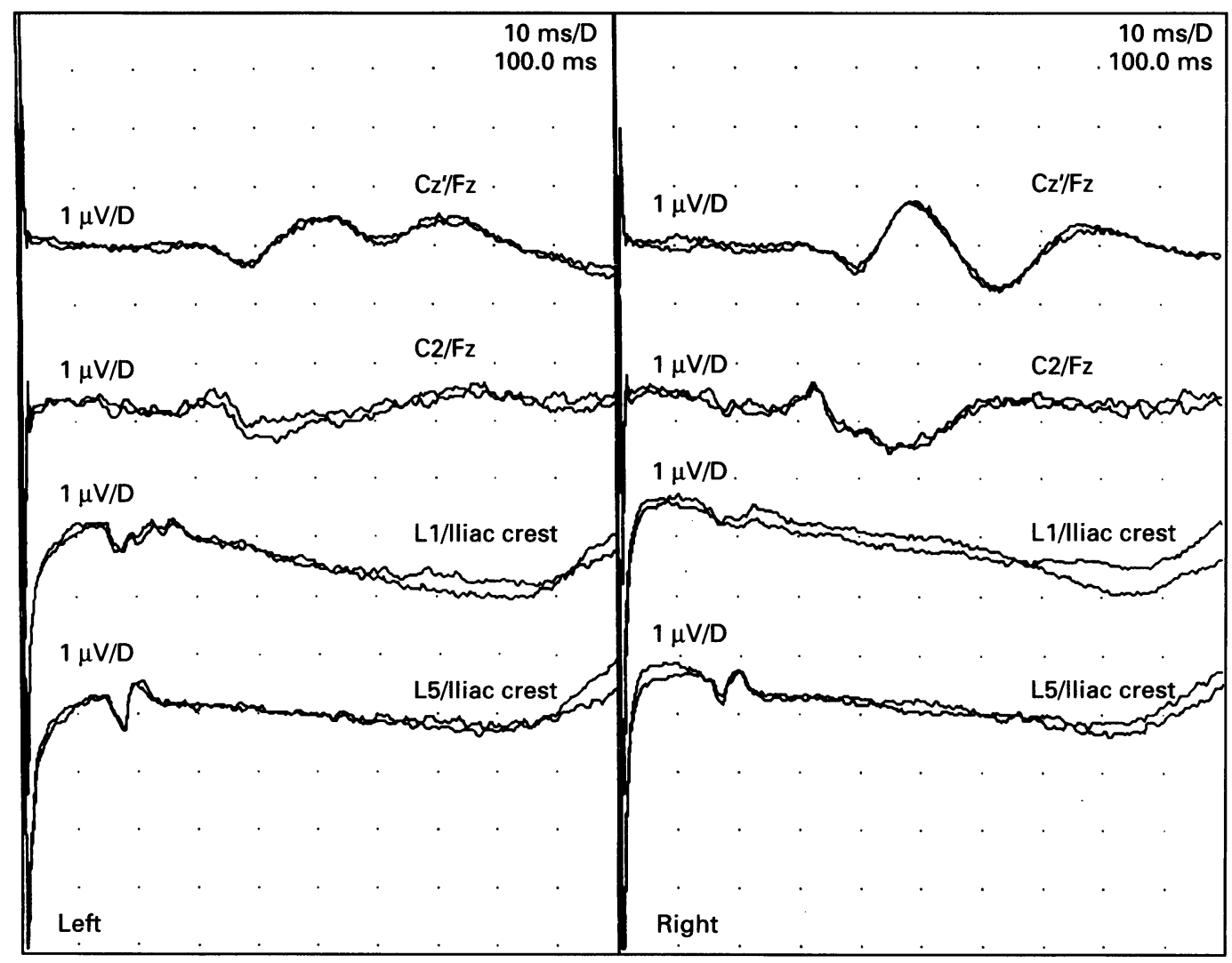


the hospital. He came back the next day because he had been unable to urinate for roughly 14 hours despite the urge to do so. In retrospect, he reported pains in the upper part of the thoracic spine several hours before the shooting practice, and, several years previously, he had had a weakness in his right leg, but this had soon disappeared. He also mentioned recurrent frontal headaches.

There was a left convex kyphoscoliosis of the thoracic spine and a right convex scoliosis of the lumbar spine. Neurological examination of the cranial nerves was unremarkable. A grade 4 paresis was found in the forearm and in the intrinsic hand muscles bilaterally, in all right leg muscles, and in the extensors and flexors of the left hip and knee. A grade 3 paresis was noted in the extensors and flexors of the left foot and toes. All deep tendon reflexes and the superficial abdominal reflexes were absent. Hypalgesia was present in C4 and C5 dermatomes bilaterally and in both hands. Hypaesthesia and hypalgesia were found in the dermatomes L5 and S1 on the right. Vibration sense was impaired in all limbs, position sense was normal. Bladder catheterisation showed $1100 \mathrm{ml}$ of residual urine.

Cerebrospinal fluid was normal. Three days after admission, regular micturition took place without any residual urine and pareses and most of the sensory deficits disappeared. Only the hypalgesia at $\mathrm{C} 4$ and $\mathrm{C5}$ dermatomes remained on both sides. A syrinx extending from the cervical to the lumbar spinal cord and a Chiari type I malformation was found by MRI. A mild hydrocephalus was also seen. In the blink reflex, R1 was absent bilaterally and R2 latency with left side stimulation was prolonged bilaterally. Amplitude of the $\mathrm{H}$ reflex in soleus muscle was low bilaterally and $\mathrm{H}$ reflex latency was prolonged on the right. Motor and sensory nerve conduction studies were normal (left median and ulnar nerve, peroneal, tibial, and sural nerve bilaterally). F Waves in abductor hallucis, extensor digitorum brevis, or hypothenar muscles, all on the left, were not elicited (at least 20 stimuli at a stimulus rate of $1 \mathrm{~Hz}$ ). In tibial nerve SEPs, no lumbar potential (N24; L1/iliac crest) could be obtained, whereas a high cervical potential (N33; C2/Fz) and a cortical $\left(\mathrm{P} 40 ; \mathrm{Cz}^{\prime} / \mathrm{Fz}\right)$ potential with a normal latency was registered. Two weeks later, a low and dispersed N24 was obtained (figure). The median nerve SEP was normal.

\section{Discussion}

The clinical course of syringomyelia is mostly slowly progressive, but acute deteriorations or partial remissions can also occur. ${ }^{2}$ A classic syndrome of pain, dissociated sensory disturbances, and brachial muscle atrophies cannot always be expected, as the neurological symptomatology depends on the extent of the syrinx. To our knowledge, reversible urinary retention as the first manifestation of syringomyelia has been only reported once, in a $2 \frac{1}{2}$ year old child. ${ }^{3}$ The authors considered that a pharmacological side effect of cyproheptadine was responsible for the reversible urinary retention. ${ }^{3}$

In the patient presented here, generalised dysaesthesiae and pareses appeared during shooting practice and urinary retention developed in the subsequent hours. Pathophysiologically, a partially transient dysfunction of the brain stem and of the entire spinal cord must have taken place, as the findings of the blink reflex, tibial SEPs, and F waves indicated. The alterations of the N24 in tibial SEPs and the lack of $F$ waves in the abductor hallucis muscle, where with a normal compound muscle action potential a near $100 \%$ persistence of $\mathrm{F}$ waves is physiologically expected, indicated dysfunction of spinal neurons in the conus medullaris. ${ }^{45}$ An analogous dysfunction of sacral parasympathetic neurons must have caused the transient urinary retention. By contrast with the spinal neurons, the function of the spinal funicles was preserved, as the normal N33 and P40 in the tibial SEP indicated. Pathogenetically, an increase in pressure within the intraspinal space and the syrinx must have occurred during shooting, when the patient held his breath (Valsalva's manoeuvre). The intraspinal pressure normalised within some seconds after return to normal breathing, but the pressure whithin the syrinx, which must have surpassed the systemic pressure in the spinal arteries, needed more time to fall and thus caused transient spinal cord ischaemia. It is possible that the intraspinal neurons are more sensitive to intraspinal hypoxia than the neuraxons of the extraspinally located pseudounipolar cells.

1 Schliep G. Syringomyelia and syringobulbia. In: Vinken PJ Bruyn GW, eds. Handbook of clinical neurology. Vol 32 Bruyn GW, eds. Handbook of clinical neurology.

2 Hertel G, Kramer S, Placzek E. Die Syringomyelie. Nervenarzt 1973;44:1-13

3 Houang M, Leroy B, Forin V, Sinnassamy P, Bensman A Retension aigue d'urines: un mode de revelation rare d'une syringomyelie cervicodorsale a l'occasion de la prise de cyproheptadine. Archives De Pediatrie 1994;1: 260-3.

4 Amoiridis G, Poehlau D, Przuntek H. Neurophysiological findings and MRI in anterior spinal artery syndrome of the lower cervical cord: the value of F-waves. 7 Neurol Neurosurg Psychiatry 1991;54:738-40.

5 Valeriani M, Restuccia D, Di Lazzaro, Tonali P. Recovery after surgery of the spinal N24 SEP in dural arteriovenous malformation of the dorsal cord. Electroencephalogr Clin Neurophysiol 1995;96:479-82. 